Published in final edited form as:

Curr Heart Fail Rep. 2008 June ; 5(2): 75-79.

\title{
Uncoupling Proteins in Heart Failure
}

\author{
Karl R. Laskowski, MD, MHS and Raymond R. Russell III, MD, PhD \\ Yale University School of Medicine
}

\begin{abstract}
The development of heart failure is associated with alterations in the expression of a wide variety of structural, signaling and metabolic proteins. One such effect is the downregulation of uncoupling proteins (UCPs) in the setting of heart failure. This group of proteins regulates the mitochondrial membrane potential and therefore plays a role in mitochondrial energy metabolism as well as reactive oxygen species generation by the mitochondria. In this review, the role of UCPs in regulating oxidant stress and implications with respect to the pathogenesis of heart failure and potential treatments will be discussed.
\end{abstract}

\section{Introduction}

The substantial prevalence and significant complications of heart failure have led to a great deal of basic and translational research concerning the pathophysiology of the disease and therapeutic options for treating heart failure $(1,2)$. Multiple studies have demonstrated that the development and progression of heart failure is associated with changes in the expression of many genes, including structural, signaling, and metabolic genes $(3,4)$. For the most part, it is not known whether these switches in gene expression, generally from adult phenotypes to fetal phenotypes (5), are beneficial or detrimental to the failing heart.

One group of proteins that are downregulated in the failing heart is the family of uncoupling proteins (UCPs), specifically UCP2 and UCP3 (6-8). As discussed in detail below, these mitochondrial membrane proteins control the mitochondrial membrane potential and consequently regulate mitochondrial ATP synthesis. In addition, UCPs also can regulate the production of reactive oxygen species by the mitochondria. Therefore, UCPs could potentially play and important role in the failing heart, due to the fact that the failing heart is challenged by both abnormalities in energy metabolism as well as enhanced oxidative stress. Both of these abnormalities may lead to apoptosis, a hallmark cellular feature of the failing heart.

In this review, we will first discuss the role of reactive oxygen species in the pathogenesis of heart failure. Based on this background of the importance of oxidant stress, we will review the function of UCPs. Finally, we will discuss the changes in UCP expression in the failing heart and the potential role of modulation of UCP expression and function in the treatment of heart failure.

\section{Reactive Oxygen Species and Heart Failure}

There is considerable evidence that damage from reactive oxygen species may play a significant role in the development and progression of congestive heart failure $(9,10)$. In patients with heart failure, markers of increased oxidant stress have been demonstrated in both

Address for correspondence: Raymond Russell, III, MD, PhD Section of Cardiovascular Medicine Yale University School of Medicine 333 Cedar Street, FMP 3 New Haven, CT 06520 Tel: 203-785-2241 Fax: 203-785-7567 Email: E-mail: raymond.russell@yale.edu. 
pericardial fluid and blood $(11,12)$. Furthermore, alterations in the ability to regulate oxidant stress have been shown to be present in patients with heart failure. Specifically, in failing hearts, decreases in the expression and activity of enzymes involved in the detoxification of reactive oxygen species, including catalase and manganese superoxide dismutase, can be observed $(13,14)$. While these changes may be the result rather than the cause of heart failure, genetic alterations of these proteins are associated with heart failure, suggesting a causal relationship. Specifically, polymorphisms in genes coding for enzymes that detoxify free radicals are associated with the development of idiopathic dilated cardiomyopathy (15-17).

Reactive oxygen species also contribute to the progression of heart failure. In addition to the serum markers of oxidant stress, increased levels of reactive oxygen species have been reported in heart tissue samples from patients with congestive heart failure (14). In a study of the role of reactive oxygen species in established heart failure in patients with hypertrophic cardiomyopathy, endomyocardial biopsy samples demonstrated that lipid peroxidation, a marker of oxidative stress, is significantly elevated in patients with hypertrophic cardiomyopathy as compared to individuals without heart failure (18). Furthermore, the level of lipid peroxidation is directly correlated with both left ventricular end-diastolic diameter and end-systolic diameter, and inversely correlated with left ventricular ejection fraction. Taken together, these data imply a pathophysiologic role for oxidative stress in the development of heart failure.

With this background, the importance of decreasing oxidant stress in the failing heart is easily understood. The efficacy of many proven heart failure therapies may involve, at least in part, protection of the myocardium from the detrimental effects of reactive oxygen species. It has been suggested that the beneficial effects of angiotensin converting enzyme inhibitors in diabetic cardiomyopathy are related to the inhibition of reactive oxygen species production through an angiotensin II-dependent pathway (19). Furthermore, there is substantial evidence that carvedilol derives some of its effectiveness through its potent antioxidant properties (20).

Animal studies have confirmed the role of ROS in the development and progression of heart failure. A transgenic mouse model with heart and skeletal muscle-specific loss of manganese superoxide dismutase develops progressive congestive heart failure with specific molecular defects in mitochondrial respiration (15). In this model, oxidative stress causes specific morphologic changes in the mitochondria, with excess formation of the reactive oxygen species, superoxide radical, reduction of ATP content, and transcriptional alterations of genes associated with heart failure. Conversely, overexpression of genes involved in the detoxification of reactive oxygen species, such as glutathione peroxidase, improve left ventricular function in mice following myocardial infarction (21). As discussed below, animal studies of heart failure and transgenic mouse models have suggested that UCPs may be important in the response of the cardiac myocyte to oxidant stress and may be a potential target for heart failure therapy.

\section{Role of Uncoupling Proteins in Regulating Reactive Oxygen Species Generation}

Uncoupling proteins are members of the superfamily of anion carrier proteins that are present in the inner mitochondrial membrane and regulate the mitochondrial membrane potential. This mitochondrial membrane potential is created by the transfer of protons, generated by citric acid cycle flux, from the mitochondrial matrix to the space between the inner and outer mitochondrial membranes through the oxidation/reduction reactions of the electron transport chain (Figure 1). This mitochondrial membrane potential drives mitochondrial ATP synthesis by $\mathrm{F}_{0} \mathrm{~F}_{1}$-ATPase, which, in turn, dissipates the mitochondrial membrane potential. Under steady-state conditions, the mitochondrial membrane potential is determined by balance 
between the efflux of protons through the electron transport chain and influx through the $\mathrm{F}_{0} \mathrm{~F}_{1}$-ATPase. The UCPs cause also dissipation of the mitochondrial membrane potential through transport of protons from the space between the inner and outer mitochondrial membranes back into the mitochondrial matrix. However, in contrast to $\mathrm{F}_{0} \mathrm{~F}_{1}$-ATPase, no ATP is synthesized by proton conductance through the UCPs and thus, they act as uncouplers of oxidative phosphorylation.

The first described uncoupling protein, UCP1 or thermogenin, was found to dissipate the proton gradient in an "energy wasting" manner, creating heat instead of the ATP. Largely restricted to brown adipose tissue, UCP1 is responsible for nonshivering thermogenesis. Subsequently, several proteins similar to UCP1 were discovered, establishing a family of UCPs. UCP2 was identified as a structural homolog of UCP1 $(22,23)$. UCP2 appears to be present in a variety of tissues throughout the body, although the presence of UCP2 protein in heart is the issue of some controversy and may be species-dependent $(24,25)$. Like UCP2, uncoupling protein 3 (UCP3) is an inner mitochondrial membrane protein with significant structural homology to the previously discovered UCP1 and is present in heart muscle. On the amino acid level, human UCP3 is $71 \%$ identical to UCP2 and $57 \%$ identical to UCP1 (26).

There are thought to be substantial differences in the function of the different UCPs $(22,26$, 27). This variation has greatly complicated the study of the UCPs and much remains to be discovered. For example, while UCP1 has been well established as being responsible for heat generation in brown fat, the physiologic roles of UCP2 and UCP3 are not thought to be involved in nonshivering thermogenesis. As a result, the functions of UCP2 and UCP3 are less certain and remain the subject of ongoing investigation and debate.

Given the structure of mitochondrial uncoupling proteins and the known function of UCP1, it is not surprising that UCP2 and UCP3 also appear mediate some degree of proton leak within the mitochondria (28). It has been proposed that the major function of these UCPs is related to other effects related to the dissipation of the mitochondrial proton gradient. Specifically, by reducing the electrical potential across the inner mitochondrial membrane, UCP2 and UCP3 can reduce production of superoxide radical at complex I of the mitochondrial respiratory chain (29). This is especially relevant to the pathophysiology of ischemia, in which insufficient oxygen is present to accept upaired electrons at complex I, thereby increasing the production of superoxide radical. In isolated skeletal mitochondria harvested from mice, reactive oxygen species production is significantly increased in UCP3 null animals compared to wild-type animals (30).

This role in mediating reactive oxygen species production and detoxification has led to the hypothesis that the UCPs protect against oxidative damage. This has been most well established in the neurologic system $(31,32)$. However, as discussed below, this effect has also been demonstrated in pathologic states in the heart, such as ischemia/reperfusion injury. In addition to protecting against "endogenous" reactive oxygen species produced by the mitochondria. UCPs may also protect against "exogenous" reactive oxygen species. Specifically, overexpression of UCP1 in cultured cardiac myocytes protects against apoptosis induced by the addition of hydrogen peroxide (33). This cytoprotective role of UCPs may be important in clinically relevant exposure to an exogenous oxidant stress, namely the cardiotoxic chemotherapeutic agent doxorubicin, which causes cardiac myocyte damage through the generation of reactive oxygen species.

\section{Uncoupling Proteins and Heart Failure: Implications and Controversy}

In developed countries, the most common cause of heart failure is ischemic heart disease. Depending on the study population and the method of investigation, the etiology of heart failure is attributed to previous myocardial infarction in approximately $50 \%$ of cases (34). Given this 
burden of ischemic cardiomyopathy, it should be noted that there is substantial literature supporting the protective effect of UCPs in ischemia/reperfusion injury (24,35-37). These studies have demonstrated that overexpression of UCPs decrease reactive oxygen species production, improve cardiomyocyte survival and improve contractile function in the setting of ischemia/reperfusion. Furthermore, these studies suggest that increasing UCP expression in the heart may represent a useful therapeutic strategy.

A recent study in a rat model has demonstrated that the degree of ischemic preconditioning is correlated with UCP2 and UCP3 expression (38). The authors demonstrated that UCP mRNA and protein expression are inversely associated with infarct size, and that UCP depletion with RNAi attenuates or abolishes myocyte recovery in vitro after anoxic insult. In a study of ischemia-induced ventricular dilation, myocardial infarction was induced in Sprague-Dawley rats resulting in a $60 \%$ increase in left ventricular end-diastolic dimension. The authors noted almost a two-fold increase in UCP2 expression in the tissue surrounding the infarct zone compared to sham-operated rats (39). Although the authors hypothesized that this increased UCP expression may be contributing to the pathologic remodeling process by inducing a lowenergy state in the surviving myocardium. However, given the cardioprotective data reviewed above, it seems more likely that the UCP upregulation is a physiologically beneficial process that prevents further myocyte death in the post-myocardial infarction period. It is of interest to note that another "low-energy state", fasting, is associated with an increase in UCP2 and UCP3 expression, suggesting that the energy wasting effect of these UCPs is negligible (40).

There is also evidence that UCPs may prevent atherosclerotic plaque formation. Reconstitution of the bone marrow of LDL-receptor deficient mice fed an atherosclerotic diet with UCP2 null bone marrow cells has been shown to result in larger atherosclerotic lesions in the aorta (41). It is believed that the UCP2 null monocytes created by the bone marrow transplantation produce more hydrogen peroxide than wild-type monocytes. This increase in hydrogen peroxide production results in greater vascular inflammation and endothelial cell activation, important initial steps in atherogenesis. In supporting a role for UCPs in protecting against atherosclerotic plaque formation, polymorphisms in the human UCP2 gene have been shown to be associated with the presence of carotid atherosclerosis (42).

In addition to the evidence that UCPs prevent ischemic damage, potentially both through slowing atherosclerosis and through decreasing oxidant stress in ischemic/reperfused cardiomyocytes, there is data suggesting that the UCPs play a critical role in heart failure itself. As discussed above, mice with cardiac deletion of manganese-superoxide dismutase develop heart failure from oxidative damage (15). In addition to the findings of enhanced oxidant stress, the authors also noted that there was decreased cardiac expression of UCP3, perhaps contributing to the pathologic process.

To investigate the role of UCPs in an animal model of heart failure, one group induced cardiac pressure overload in rats by banding the ascending aorta. After one week, both UCP2 and UCP3 expression on the mRNA level were significantly reduced (6). Furthermore, pressure unloading by heterotopically transplanting rat hearts to the abdomal aorta of a recipient rat resulted in decreased UCP2 and UCP3 mRNA expression in the unloaded, transplanted heart(6). In another study, heart failure was induced in rats by creating severe aortic regurgitiation. Somewhat surprisingly, UCP2 was observed to initially decrease, but then increased significantly compared to sham-operation control rats (43). While the differences explaining the results of these studies are not readily apparent, it is clear that these findings indicate that hemodynamic perturbations, either overloading or underloading, alter the expression of UCPs in the heart. 
Studies from human heart samples have confirmed the fact that heart failure results in a decrease in UCP3 expression. A recent study of 14 human subjects with heart failure, including both ischemic and nonischemic cardiomyopathy, who had placement and subsequent removal of a left ventricular assist device (LVAD) compared pre- and post-LVAD UCP levels with those from normal donor hearts (7). There was significantly lower UCP3 mRNA expression in the pre-LVAD failing hearts compared to control tissue. Furthermore, after treatment with the LVAD, the UCP 3 mRNA content normalized. Interestingly, the change in UCP2 mRNA expression in the failing hearts did not change significantly. There remains some question as to whether the correlation between UCP2 expression on the mRNA level correlates with expression on the protein level because of post-transcriptional regulation.

Controversy remains as to whether UCPs play a beneficial or detrimental role, particularly in the setting of heart failure because downregulation of UCPs in the failing heart could have theoretically opposing effects. A decrease in UCP expression would be expected to enhance the coupling between citric acid cycle flux and mitochondrial ATP synthesis, this enhanced energetic efficiency would be important in cardiomyocytes that are energetically stressed through the many effects of heart failure. However, deceased UCP expression would also have the counterbalancing effect of allowing greater production of reactive oxygen species.

The question then become one of whether downregulation of UCP expression in the failing heart is maladaptive and should therapies be developed to increase UCP expression. Would the shunting of protons away from ATP production by increasing UCP expression contribute to a low-energy state $(44,45)$ ? However, it has been argued that, in addition to preventing oxidant stress and cardiomyocyte damage, the metabolic effects of the UCPs are actually beneficial to the failing heart, and represent an adaptive response to lipid accumulation within the mitochondria and subsequent toxicity, and not a maladaptive response (46).

If it is found that the beneficial effects of enhancing UCP expression in the failing heart predominate, several potential therapeutic options are available. UCP expression in the heart is regulated, in part, through peroxisome proliferators-activated receptor (PPAR) $\alpha$-mediated mechanisms (6). As interest continues in the development of PPAR- $\gamma / \alpha$ agonists for the treatment of diabetes, the use of these agents to increase UCP expression in the heart may be evaluated. In addition, UCP expression can be increased in muscle through activation of AMPactivated protein kinase (AMPK), a signaling protein kinase that responds to metabolic stress $(47,48)$. Because of the role of AMPK in cardiomyocyte survival in response to ischemia/ reperfusion (49), this may also represent an important target for increasing UCP expression in the failing heart.

\section{Conclusions}

Heart failure remains a significant problem as we begin the $21^{\text {st }}$ century. Despite the impact of heart failure, the pathogenesis is still not well understood. There is significant evidence that ROS-mediated damage is involved in the molecular processes responsible for the disease, although many equally compelling and seemingly competing hypotheses exist. Experimental evidence has demonstrated that the UCPs prevent ROS accumulation by limiting production, and that they may play a role in the detoxification of exogenously produced ROS. While there is some conflicting evidence, it seems that UCP2 and UCP3 are often decreased in both animal models of heart failure and in human clinical samples. More research needs to be undertaken to more clearly elucidate the role of UCPs in heart failure. However, the UCPs seem to represent a promising target for manipulation of the disease. 


\section{Acknowledgment}

This work was supported, in part, from a grant from the National Institutes of Health (HL077310).

\section{References}

1. Benjamin IJ, Schneider MD. Learning from failure: congestive heart failure in the postgenomic age. J. Clin. Invest 2005;115:495-499. [PubMed: 15765130]

2. deGoma EM, Vagelos RH, Fowler MB, Ashley EA. Emerging therapies for the management of decompensated heart failure: from bench to bedside. J Am Coll Cardiol 2006;48:2397-2409. [PubMed: 17174176]

3. Hwang JJ, Allen PD, Tseng GC, Lam CW, Fananapazir L, Dzau VJ, Liew CC. Microarray gene expression profiles in dilated and hypertrophic cardiomyopathic end-stage heart failure. Physiol Genomics 2002;10:31-44. [PubMed: 12118103]

4. Chen Y, Park S, Li Y, Missov E, Hou M, Han X, Hall JL, Miller LW, Bache RJ. Alterations of gene expression in failing myocardium following left ventricular assist device support. Physiol Genomics 2003;14:251-260. [PubMed: 12824457]

5. Depré C, Shipley GL, Chen W, Han Q, Doenst T, Moore ML, Stepkowski S, Davies PJ, Taegtmeyer $\mathrm{H}$. Unloaded heart in vivo replicates fetal gene expression of cardiac hypertrophy. Nat Med 1998;4:1269-1275. [PubMed: 9809550]

6. Young ME, Patil S, Ying J, Depre C, Ahuja HS, Shipley GL, Stepkowski SM, Davies PJ, Taegtmeyer $\mathrm{H}$. Uncoupling protein 3 transcription is regulated by peroxisome proliferator-activated receptor $\alpha$ in the adult rodent heart. FASEB J 2001;15:833-845. [PubMed: 11259402]

7. Razeghi P, Young ME, Ying J, Depre C, Uray IP, Kolesar J, Shipley GL, Moravec CS, Davies PJ, Frazier $\mathrm{OH}$, et al. Downregulation of metabolic gene expression in failing human heart before and after mechanical unloading. Cardiology 2002;97:203-209. [PubMed: 12145475]

8. Taegtmeyer H, Razeghi P, Young ME. Mitochondrial proteins in hypertrophy and atrophy: a transcript analysis in rat heart. Clin Exp Pharmacol Physiol 2002;29:346-650. [PubMed: 11985548]

•9. Giordano FJ. Oxygen, oxidative stress, hypoxia, and heart failure. J. Clin. Invest 2005;115:500508.508 [PubMed: 15765131]This is a very comprehensive review of myocyte oxidant stress and its implications with respect to heart failure.

10. Givertz MM, Colucci WS. New targets for heart-failure therapy: endothelin, inflammatory cytokines, and oxidative stress. Lancet 1998;352(Suppl 1):SI34-38. [PubMed: 9736478]

11. Diaz-Velez CR, Garcia-Castineiras S, Mendoza-Ramos E, Hernandez-Lopez E. Increased malondialdehyde in peripheral blood of patients with congestive heart failure. Am Heart $\mathbf{J}$ 1996;131:146-152. [PubMed: 8554002]

12. Mallat Z, Philip I, Lebret M, Chatel D, Maclouf J, Tedgui A. Elevated levels of 8-iso-prostaglandin F2alpha in pericardial fluid of patients with heart failure: a potential role for in vivo oxidant stress in ventricular dilatation and progression to heart failure. Circulation 1998;97:1536-1539. [PubMed: 9593557]

13. Baumer AT, Flesch M, Wang X, Shen Q, Feuerstein GZ, Bohm M. Antioxidative enzymes in human hearts with idiopathic dilated cardiomyopathy. Journal of Molecular \& Cellular Cardiology 2000;32:121-130. [PubMed: 10652196]

14. Sam F, Kerstetter DL, Pimental DR, Mulukutla S, Tabaee A, Bristow MR, Colucci WS, Sawyer DB. Increased reactive oxygen species production and functional alterations in antioxidant enzymes in human failing myocardium. J Card Fail 2005;11:473-480. [PubMed: 16105639]

-15. Nojiri H, Shimizu T, Funakoshi M, Yamaguchi O, Zhou H, Kawakami S, Ohta Y, Sami M, Tachibana $\mathrm{T}$, Ishikawa $\mathrm{H}$, et al. Oxidative stress causes heart failure with impaired mitochondrial respiration. J Biol Chem 2006;281:33789-33801.33801 [PubMed: 16959785]This study characterizes the mitochondrial dysfunction that occurs with oxidant stress and the role of these energetic changes in the pathophysiology of heart failure.

16. Hiroi S, Harada H, Nishi H, Satoh M, Nagai R, Kimura A. Polymorphisms in the SOD2 and HLADRB1 genes are associated with nonfamilial idiopathic dilated cardiomyopathy in Japanese. Biochem Biophys Res Commun 1999;261:332-339. [PubMed: 10425186] 
17. Valenti L, Conte D, Piperno A, Dongiovanni P, Fracanzani AL, Fraquelli M, Vergani A, Gianni C, Carmagnola L, Fargion S. The mitochondrial superoxide dismutase A16V polymorphism in the cardiomyopathy associated with hereditary haemochromatosis. J Med Genet 2004;41:946-950. [PubMed: 15591282]

18. Nakamura K, Kusano KF, Matsubara H, Nakamura Y, Miura A, Nishii N, Banba K, Nagase S, Miyaji $\mathrm{K}$, Morita $\mathrm{H}$, et al. Relationship between oxidative stress and systolic dysfunction in patients with hypertrophic cardiomyopathy. J Card Fail 2005;11:117-123. [PubMed: 15732031]

19. Ye G, Metreveli NS, Ren J, Epstein PN. Metallothionein prevents diabetes-induced deficits in cardiomyocytes by inhibiting reactive oxygen species production. Diabetes 2003;52:777-783. [PubMed: 12606520]

20. Kawai K, Qin F, Shite J, Mao W, Fukuoka S, Liang CS. Importance of antioxidant and antiapoptotic effects of beta-receptor blockers in heart failure therapy. Am J Physiol Heart Circ Physiol 2004;287:H1003-1012. [PubMed: 15105169]

21. Shiomi T, Tsutsui H, Matsusaka H, Murakami K, Hayashidani S, Ikeuchi M, Wen J, Kubota T, Utsumi $\mathrm{H}$, Takeshita A. Overexpression of glutathione peroxidase prevents left ventricular remodeling and failure after myocardial infarction in mice. Circulation 2004;109:544-549. [PubMed: 14744974]

22. Fleury C, Neverova M, Collins S, Raimbault S, Champigny O, Levi-Meyrueis C, Bouillaud F, Seldin MF, Surwit RS, Ricquier D, et al. Uncoupling protein-2: a novel gene linked to obesity and hyperinsulinemia. Nat Genet 1997;15:269-272. [PubMed: 9054939]

23. Gimeno RE, Dembski M, Weng X, Deng N, Shyjan AW, Gimeno CJ, Iris F, Ellis SJ, Woolf EA, Tartaglia LA. Cloning and characterization of an uncoupling protein homolog: a potential molecular mediator of human thermogenesis. Diabetes 1997;46:900-906. [PubMed: 9133562]

-24. Sack MN. Mitochondrial depolarization and the role of uncoupling proteins in ischemia tolerance. Cardiovascular Research 2006;72:210-219.219 [PubMed: 16914124]An excellent review of the role of uncoupling proteins in the heart and their cardioprotective role in the setting of ischemia/ reperfusion.

25. Murray AJ, Anderson RE, Watson GC, Radda GK, Clarke K. Uncoupling proteins in human heart. The Lancet 2004;364:1786-1788.

26. Vidal-Puig A, Solanes G, Grujic D, Flier JS, Lowell BB. UCP3: an uncoupling protein homologue expressed preferentially and abundantly in skeletal muscle and brown adipose tissue. Biochem Biophys Res Commun 1997;235:79-82. [PubMed: 9196039]

27. Matsuda J, Hosoda K, Itoh H, Son C, Doi K, Tanaka T, Fukunaga Y, Inoue G, Nishimura H, Yoshimasa $\mathrm{Y}$, et al. Cloning of rat uncoupling protein-3 and uncoupling protein-2 cDNAs: their gene expression in rats fed high-fat diet. FEBS Lett 1997;418:200-204. [PubMed: 9414126]

28. Douette P, Sluse FE. Mitochondrial uncoupling proteins: new insights from functional and proteomic studies. Free Radic Biol Med 2006;40:1097-1107. [PubMed: 16545677]

29. Liu SS. Generating, partitioning, targeting and functioning of superoxide in mitochondria. Biosci Rep 1997;17:259-272. [PubMed: 9337481]

30. Vidal-Puig AJ, Grujic D, Zhang CY, Hagen T, Boss O, Ido Y, Szczepanik A, Wade J, Mootha V, Cortright R, et al. Energy metabolism in uncoupling protein 3 gene knockout mice. J Biol Chem 2000;275:16258-16266. [PubMed: 10748196]

31. Mattiasson G, Shamloo M, Gido G, Mathi K, Tomasevic G, Yi S, Warden CH, Castilho RF, Melcher $\mathrm{T}$, Gonzalez-Zulueta $\mathrm{M}$, et al. Uncoupling protein-2 prevents neuronal death and diminishes brain dysfunction after stroke and brain trauma. Nat Med 2003;9:1062-1068. [PubMed: 12858170]

32. Bechmann I, Diano S, Warden CH, Bartfai T, Nitsch R, Horvath TL. Brain mitochondrial uncoupling protein 2 (UCP2): a protective stress signal in neuronal injury. Biochem Pharmacol 2002;64:363367. [PubMed: 12147286]

33. Teshima Y, Akao M, Jones SP, Marban E. Uncoupling protein-2 overexpression inhibits mitochondrial death pathway in cardiomyocytes. Circ Res 2003;93:192-200. [PubMed: 12855674]

34. Fox KF, Cowie MR, Wood DA, Coats AJ, Gibbs JS, Underwood SR, Turner RM, Poole-Wilson PA, Davies SW, Sutton GC. Coronary artery disease as the cause of incident heart failure in the population. Eur Heart J 2001;22:228-236. [PubMed: 11161934]

35. Bienengraeber M, Ozcan C, Terzic A. Stable transfection of UCP1 confers resistance to hypoxia/ reoxygenation in a heart-derived cell line. J Mol Cell Cardiol 2003;35:861-865. [PubMed: 12818577] 
36. Hoerter J, Gonzalez-Barroso M.-d.-M. Couplan E, Mateo P, Gelly C, Cassard-Doulcier A-M, Diolez $\mathrm{P}$, Bouillaud F. Mitochondrial uncoupling protein 1 expressed in the heart of transgenic mice protects against ischemic-reperfusion damage. Circulation 2004;110:528-533. [PubMed: 15262832]

37. Bodyak N, Rigor DL, Chen YS, Han Y, Bisping E, Pu WT, Kang PM. Uncoupling Protein-2 Modulates Cell Viability in Adult Rat Cardiomyocytes. Am J Physiol Heart Circ Physiol. 2007

$\bullet$ •38. McLeod CJ, Aziz A, Hoyt RF Jr. McCoy JP Jr. Sack MN. Uncoupling proteins 2 and 3 function in concert to augment tolerance to cardiac ischemia. J Biol Chem 2005;280:33470-33476.33476 [PubMed: 16079144]This study demonstrates the protective role of UCPs in ischemia/reperfusion injury and demonstrates that UCP expression is upregulated with ischemic preconditioning. Furthermore, the study demonstrates that decreasing UCP expression attenuates the preconditioning effect and increases reactive oxygen species production.

39. Guo P, Mizushige K, Noma T, Murakami K, Namba T, Ishizawa M, Tsuji T, Kimura S, Kohno M. Association of uncoupling protein-2 expression with increased reactive oxygen species in residual myocardium of the enlarged left ventricle after myocardial infarction. Heart Vessels 2005;20:61-65. [PubMed: 15772780]

40. Boss O, Samec S, Dulloo A, Seydoux J, Muzzin P, Giacobino JP. Tissue-dependent upregulation of rat uncoupling protein-2 expression in response to fasting or cold. FEBS Lett 1997;412:111-114. [PubMed: 9257701]

41. Blanc J, Alves-Guerra MC, Esposito B, Rousset S, Gourdy P, Ricquier D, Tedgui A, Miroux B, Mallat Z. Protective role of uncoupling protein 2 in atherosclerosis. Circulation 2003;107:388-390. [PubMed: 12551860]

••42. Oberkofler H, Iglseder B, Klein K, Unger J, Haltmayer M, Krempler F, Paulweber B, Patsch W. Associations of the UCP2 Gene Locus With Asymptomatic Carotid Atherosclerosis in Middle-Aged Women. Arterioscler Thromb Vasc Biol 2005;25:604-610.610 [PubMed: 15604415]This study demonstrated that polymorphisms in the UCP2 gene are associated with atherosclerotic burden, presumably through the regulation of hydrogen peroxide production of monocytes that can cause vascular inflammation.

43. Noma T, Nishiyama A, Mizushige K, Murakami K, Tsuji T, Kohno M, Rahman M, Fukui T, Abe Y, Kimura S. Possible role of uncoupling protein in regulation of myocardial energy metabolism in aortic regurgitation model rats. Faseb J 2001;15:1206-1208. [PubMed: 11344089]

44. Neubauer S. The failing heart--an engine out of fuel. N Engl J Med 2007;356:1140-1151. [PubMed: 17360992]

45. Ashrafian H, Frenneaux MP, Opie LH. Metabolic mechanisms in heart failure. Circulation 2007;116:434-448. [PubMed: 17646594]

46. Hesselink MK, Schrauwen P. Uncoupling proteins in the failing human heart: friend or foe? Lancet 2005;365:385-386. [PubMed: 15680450]

47. Zhou M, Lin BZ, Coughlin S, Vallega G, Pilch PF. UCP-3 expression in skeletal muscle: effects of exercise, hypoxia, and AMP-activated protein kinase. Am J Physiol 2000;279:E622-E629.

48. Stoppani J, Hildebrandt AL, Sakamoto K, Cameron-Smith D, Goodyear LJ, Neufer PD. AMPactivated protein kinase activates transcription of the UCP3 and HKII genes in rat skeletal muscle. Am J Physiol 2002;283:E1239-E1248.

49. Russell RR III, Li J, Coven DL, Pypaert M, Zechner C, Palmeri M, Giordano FJ, Mu J, Birnbaum MJ, Young LH. AMP-activated protein kinase mediates ischemic glucose uptake and prevents postischemic cardiac dysfunction, apoptosis, and injury. J Clin Invest 2004;114:495-503. [PubMed: 15314686] 


\section{OMM}

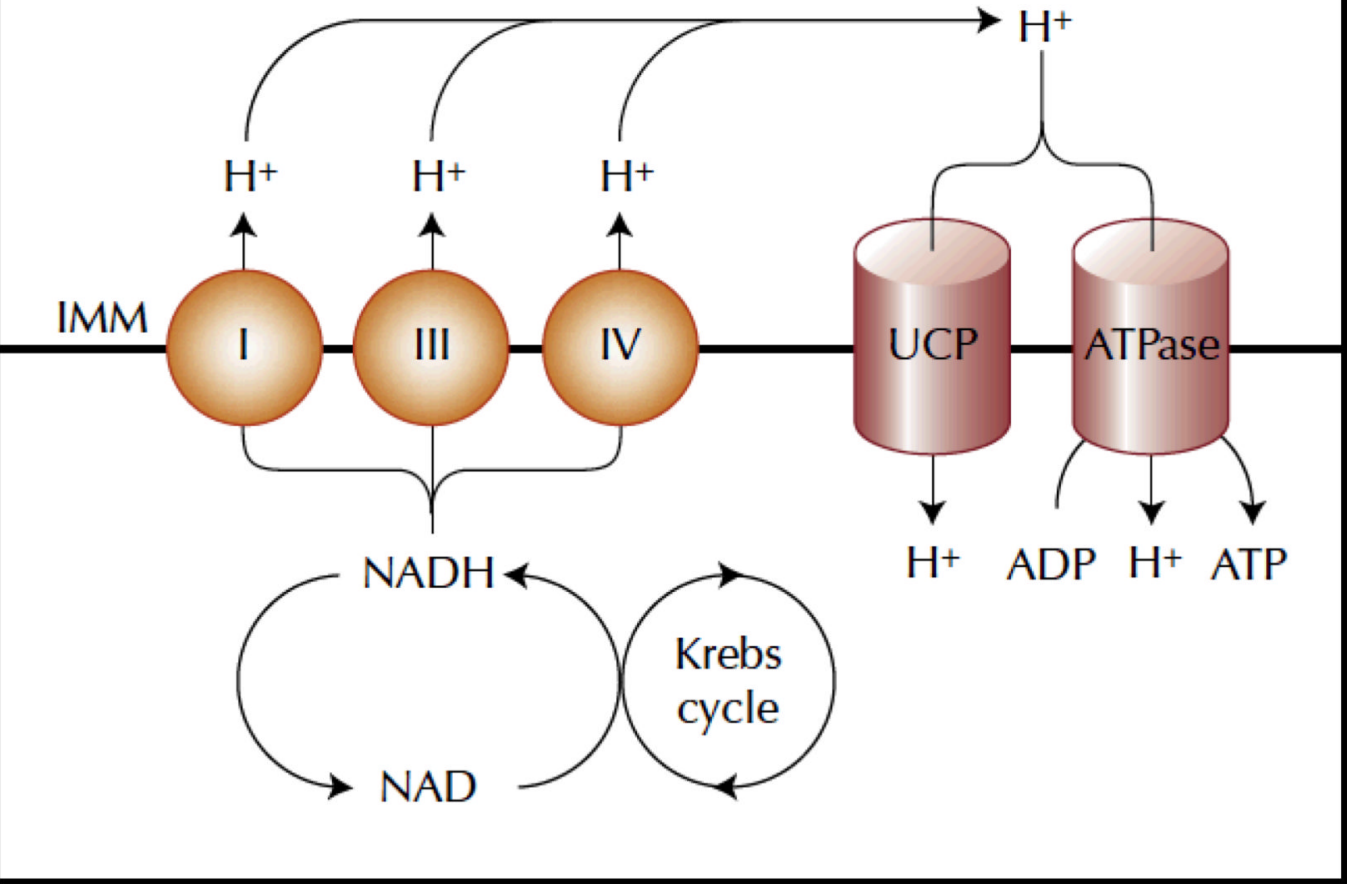

1..

Mitochondrial metabolism and the role of uncoupling proteins (UCP) in regulating the mitochondrial membrane potential. The Krebs cycle, as well as the $\beta$-oxidation of fatty acids, generates NADH and FADH, which are reoxidized to NAD and FAD by the respiratory chain complexes (I, III, IV) with the transfer of protons from the mitochondrial matrix to the space between the inner mitochondrial membrane (IMM) and the outer mitochondrial membrane $(\mathrm{OMM})$. These protons are transported back to the mitochondrial matrix via $\mathrm{F}_{0} \mathrm{~F}_{1}$-ATPase or UCP. In contrast to $\mathrm{F}_{0} \mathrm{~F}_{1}$-ATPase, the transport of protons via UCP does not synthesize ATP. 